\title{
Proposal And Validity Of Patent Evaluation Method - A-PPM - For Corporate Strategy
}

Koichiro Anabuki, Aoyama Gakuin University, Japan Haruhiko Kaneta, Aoyama Gakuin University, Japan Kakuro Amasaka, Aoyama Gakuin University, Japan

\begin{abstract}
In this paper, a patent value evaluation method, which is part of corporate strategy; namely, " $A$ PPM" (Amasakalab's - Patent Performance Method), is proposed. Improvement in the "patent value" indicates value creation for the engineers' work. Based on the keyword "strategically competitive patent", 14 component factors necessary for patent value evaluation were defined in an effort to structure a "patent evaluation method" for qualitatively evaluating patents. Engineers, the intellectual property department, or chartered patent agents involved in the development of patents generally have different viewpoints about patent evaluation. Therefore, by conducting the evaluation separately in order to obtain a more detailed evaluation and then integrating these evaluation results, the creation of patents of higher value can be ensured. This way, the "Patent Evaluation Method - A-PPM" was established to innovate intellectual property functions and thereby enhance the competitiveness of corporate strategy. Its effectiveness has also been verified at a leading corporation.
\end{abstract}

Keywords: Patent Evaluation Method - A-PPM; patent value; qualitative evaluating patents

\section{THE SIGNIFICANCE OF PATENT ACQUISITION AS A PART OF CORPORATE TECHNOLOGICAL STRATEGY}

\section{The Current Situation Of Patent Applications In Japan}

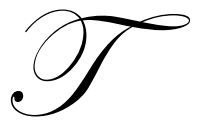

he number of patent applications in Japan in recent years is about 400,000. Of these, about $30 \%$ are actually implemented and the rest - about $70 \%$ - are said to be "dormant patents". This situation is brought about by the fact that defensive patents account for $40 \%$ or more of the patent applications which are not intended for commercial applications.

Recently, the number of patent applications has been declining. All over Japan, there has been a shift from a phase of numerous applications to that of selective applications. However, a specific methodology for selecting a highly effective patent is not available at this time, and this is sorely needed in different industrial fields.

\section{Corporate Reform And Patent Acquisition}

One of today's most relevant issues concerning corporate technological strategy is to conduct cutting-edge and innovative technological development from both a mid- and long-term standpoint with a view to improving the quality of patents so that patents that are exclusive and competitively superior can be acquired. Progressiveness and freshness are always required of a "patent". Therefore, the significance of patent acquisition is for engineers to create and realize strategic technologies with proactive ideas (ingenuity).

The activities of such engineers in creating a "patent" while searching for new technologies also promote self-growth and contribute greatly to the innovation and development of corporations. In this way, the intellectual 
productivity of white collar workforces can be improved. Moreover, the act of "invention and patent registration", while being conscious of corporate strategy, can also be an essential basis of corporate strategy.

\section{AN ISSUE FOR THE INTELLECTUAL PROPERTY DEPARTMENT, “QUALITATIVE EVALUATION OF PATENT VALUE”}

Based on the idea that, "a good patent is a product of good development", in order to acquire a strong and wide-ranging patent, the conventional issues involved have been (1) the patent management system (from quantity to quality), (2) reinforcement of patent acquisition support for the development departments, and (3) improvement in the capabilities of the intellectual property department staff. However, at the core of these fundamental issues is the fact that there was no systematic and effective "patent evaluation methods" emphasizing strategic competitiveness with regard to the four elements necessary for developing "technological patents for commercialization".

These four elements are: 1) product power, 2) practicality, 3) strength of right, and 4) technological development capabilities. The main reason for such a situation is that the methodology for 1) engineers (inventors) who create patents and their superiors, 2) the intellectual property department (patent examiners) who decide whether or not to apply for the patents, and 3) chartered patent agents (outsourced experts) who prepare the "patent" application forms, to qualitatively assess and evaluate the "patent value" based on objective evaluation standards has been insufficient.

In the conventional "quality evaluation of patents", which is dependent on the empirical rules of the three different evaluating groups 1,2, and 3 above, the intention of development engineers concerning the "four elements of patent application" cannot be sufficiently appreciated by their superiors, the patent management staff, patent examiners, and chartered patent agents. As a result, the rejection of patent examination filings, a mismatch between the content of the invention and the scope of the patent claims, and the deteriorating quality of the patent due to restrictions has been observed from time to time. Such a problem in the process of patent creation has not been effectively solved, and therefore technological development, which is supposed to strengthen corporate strategy, is being delayed and is not resulting in the continual creation of strategic patents. This also interferes with the improvement of intellectual productivity.

Generally, a "strategically effective patent" is said to be the kind of invention or right that develops the company's business operations, influences competitors, and brings the company into a superior position. However, as far as the authors are aware of, there have not been any studies on "qualitative evaluation of patent value". For example, many of the studies on patents are limited to statistical analyses, mainly for the stratified categorization of patent development trends or the contents of inventions developed by corporations and inventors.

Some considerations of the value (cash flow) of intellectual property have been done in the past, but mainly for calculating the monetary value of a patent, and not for promoting the growth of technology or improving the quality of patents. According to the hearing the authors conducted with five manufacturers, 12 chartered patent agents, Japan Patent Attorneys, and the Patent Office, disparities were observed in their subjective evaluations since these were based on their own experiences. Against this background, establishment of a consistent "qualitative evaluation of patent value" is eagerly anticipated from a variety of relevant industrial circles.

\section{STRATEGIC PATENTS}

\section{Grasping The Potential Structures Of A "Strategically Effective Patent"}

The authors conducted a questionnaire survey of engineers working for an advanced manufacturer - Toyota - (97 engineers from seven departments; two from R \& D, one from Designing, two from Production Engineering, one from Machinery \& Tools, and two from Management) whose development or inventions have been patented for the purpose of finding out "what is a strategically effective patent for corporations". Based on the analysis of the collected linguistic information (by means of cluster analysis and factor analysis), potential structures to be considered were clarified. These structures included the 1) Realistic group (emphasizing profit), 2) Preemptive group (opting for originality), and 3) Innovative group (trying to be advanced). 
Furthermore, new knowledge was obtained which suggests that the values (recognition) of engineers concerning what makes an effective patent differ according to their assigned department ( $\mathrm{R} \& \mathrm{D}$, production engineering, manufacturing, etc.) or according to their research history (practicality, superiority to competitors, initiative-minded, etc.). Through this analysis, we gained a clue for establishing the "patent evaluation method".

\section{Grasping Engineers' Values With Regard To Strategic Patents}

Similarly, in connection with the previously mentioned "dormant patents", the authors made an investigation at Toyota about the change in the engineers" consciousness (values) toward "simply good patents", contemplated by engineers on a daily basis for acquiring "patents", and "strategically effective patents", that are designed to strengthen the corporate technological strategy.

As a result, a new understanding was gained through factor analyses and other methods about the aforementioned "four elements of patent application". The results indicated that the "simply good patents" generally tend to focus on "1) product power and 2) practicality", whereas the emphasis of "strategically effective patents" shifts to focus on "3) authoritativeness of rights and 4) technological development capabilities".

\section{PROPOSAL OF PATENT EVALUATION METHOD, “A-PPM"}

Based on the knowledge acquired above, we hereby propose the "Patent Evaluation Method, "A-PPM"' which supports the creation of strategic patents as a basis of corporate strategy.

\section{Redefinition Of The Patent Evaluation Variables}

The relevant factors (explanation variables, X1 to X11) from the linguistic information gathered from Toyota were extracted and summarized. Moreover, based on the hearings conducted by the authors, the idea was brought forth that, for evaluation of patents, an international viewpoint, as well as a time-series viewpoint, might be necessary in addition to the 11 explanation variables. Fourteen total variables (X1 to X14) were defined as explaining strategic patents, as shown in Table 1.

\section{Grasping Patent Evaluation And The Potential Factors}

It has been established through the hearings conducted by the authors that engineers, the intellectual property department, and chartered patent agents are separately evaluating patents based upon their own empirical rules.

Here, the disagreement in the opinions of these three groups is one of the causes of the declining quality of patents. For the purpose of investigating what is given priority when these three groups evaluate "strategic patents", and also to clarify the importance of and relationships between the 14 evaluation indices, we prepared a 7-point scoring questionnaire (7=extremely important, $6=$ fairly important, $5=$ important, $4=$ neither important nor unimportant, $3=$ =unnecessary, $2=$ fairly unnecessary, and $1=$ extremely unnecessary) and conducted a survey targeting 69 participants (40 engineers, 17 intellectual property department staff, and 12 chartered patent agents).

As a result of a cluster analysis based on the survey, all three groups surveyed - engineers, intellectual property department staff, and chartered patent agents - can be clustered into five groups. However, there was a difference in the way the explanation variables were divided among the three groups. In other words, these three groups emphasize different points when evaluating a patent.

Having said that, assuming that these five separate groups are potential factors for patent evaluation, attempts were then made to grasp the implications of these results. 
Table 1: Explanation Variables Of "Strategic Patents"

\begin{tabular}{|l|l|}
\hline & Evaluation Indices \\
\hline $\mathrm{X} 1$ & Technological lead ahead of competitors \\
\hline $\mathrm{X} 2$ & International technological lead \\
\hline $\mathrm{X} 3$ & Technological superiority to own company's alternative technology \\
\hline $\mathrm{X} 4$ & Product appeal \\
\hline $\mathrm{X} 5$ & Applicability \\
\hline $\mathrm{X} 6$ & Profitability \\
\hline $\mathrm{X} 7$ & Innovativeness \\
\hline $\mathrm{X} 8$ & Fundamental idea \\
\hline $\mathrm{X} 9$ & Abundance of cases \\
\hline $\mathrm{X} 10$ & Patent right-based influence on competitors \\
\hline $\mathrm{X} 11$ & International patent right-based influence \\
\hline $\mathrm{X} 12$ & Exhaustiveness of the patent's scope \\
\hline $\mathrm{X} 13$ & Trendiness \\
\hline $\mathrm{X} 14$ & Patent's consideration of the future of the company \\
\hline
\end{tabular}

\section{Grasping The Potential Factors Of Chartered Patent Agents}

Figure 1 shows the cluster analysis results of the questionnaire survey for the chartered patent agents. The first group of chartered patent agents herein is comprised of X1, X2, X6 and X12. This one can be interpreted as a concern with technological ability that puts emphasis on profitability and the exhaustive coverage of the patent's scope.

Therefore, it can be considered as a potential factor related to [A1: Technological capability]. Similarly, the group made up of $\mathrm{X} 7, \mathrm{X} 8, \mathrm{X} 9$, and $\mathrm{X} 13$ focuses on innovative ideas while considering the current trends, and thus emphasis is given to [A2: Idea].

The group made up of X10, X11, and X14 is a group concerned about the patent right's influence on the company's future, giving emphasis to [A3: Patent right-based influence], and the group focused on X4 and X5 is concerned about the product appeal as well as the development and application possibilities of patents. Therefore, they can be categorized as [A4: Flexibility], while the X3 group highly values [A7: alternative technology].

\section{Grasping The Potential Factors Of Development Engineers}

The potential factors were clarified for these groups in the same way as above. The first group from the engineers, which opted for $\mathrm{X} 1, \mathrm{X} 2$, and $\mathrm{X} 3$, is considered to be a factor that gives emphasis to [A1: Technological capability]. The group choosing X7, X8, and X14 indicates that they put emphasis on [A2: Idea]. The group highly valuing X6, X10, X11, and X12 put emphasis on [A3: Patent right-based influence].

The group which chose X4 and X5 put emphasis on [A4: Flexibility] and the group which chose X9 and $\mathrm{X} 13$ put the most emphasis on [A5: Trendiness].

\section{Grasping The Potential Factors Of The Intellectual Property Department Staff}

The potential factors were clarified for this group the same as above. The group opting for $\mathrm{X} 1, \mathrm{X} 2$, and $\mathrm{X} 7$ is considered to be a factor that gives emphasis to [A1: Technological capability]. 


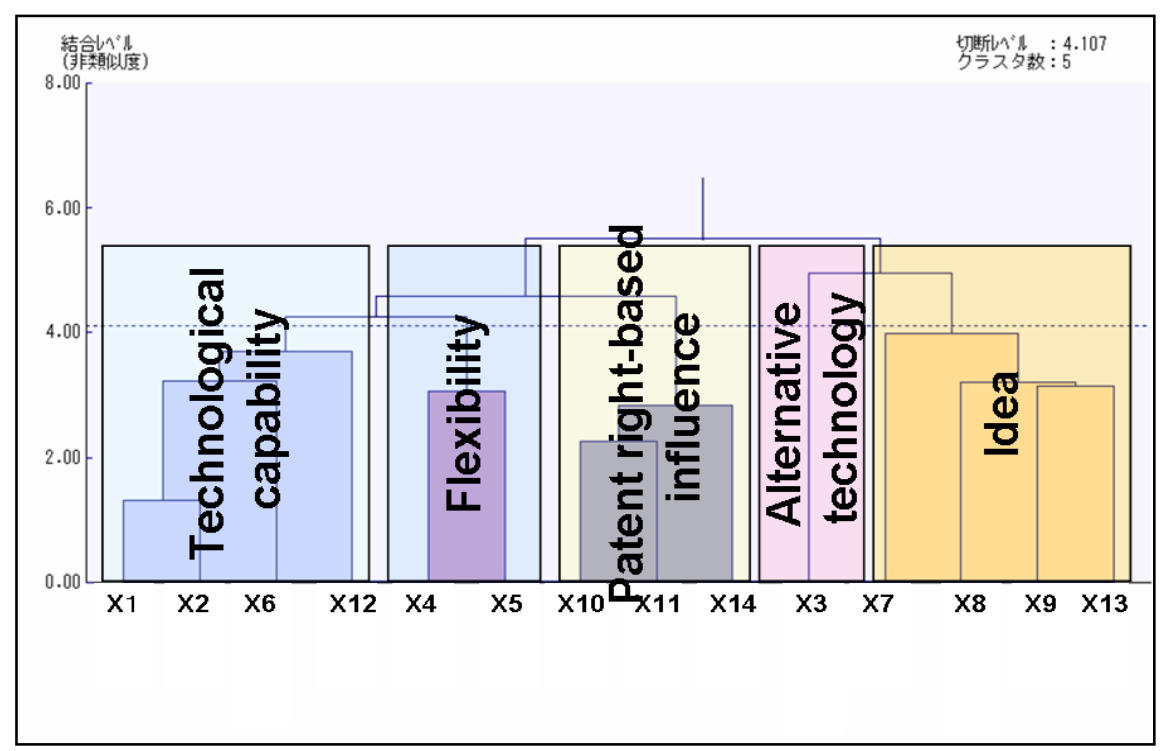

Figure 1: Cluster Analysis Results For The Chartered Patent Agents

The group that chose $\mathrm{X} 3, \mathrm{X} 4$, and $\mathrm{X} 8$ is putting emphasis on [A2: Idea]. The group which chose $\mathrm{X} 6, \mathrm{X} 10$, and X11 is most concerned about [A3: Patent right-based influence]. The group which chose X5, X13, and X14 puts emphasis on [A4: Flexibility], and the group which chose X9 and X12 highly values the [A6: Exhaustive Coverage of the Patent's Scope].

The evaluation indices from A1 to A4 are factors common to all three groups, but the fifth factor proved to be different. The thinking behind it is something common to all types of specialties. For example, the main job of chartered patent agents is to prepare descriptions of patents, but what they are most concerned about is whether or not the same technology already exists.

The potential factor that was revealed for chartered patent agents is a reflection of such thinking. In other words, the fifth factor is a point which deserves attention from each group or department, and thus can be considered to be an important index.

\section{The Structure Of The Patent Evaluation Method Model Equation}

As shown in the analysis results, patent evaluation based on the 14 indices has been proven to have its basis in the five potential factors of each evaluating group. It was thought that by investigating the relationships between the 14 evaluation indices and the five potential factors, as well as the relationships between the potential factors and the patent strength, an evaluation method might be constructed.

Consequently, covariance structure analysis was used by considering the five potential factors as primary potential factors and [comprehensive patent strength] as a secondary potential factor in order to investigate their relationship.

Using the partial regression coefficient calculated from the covariance structure, evaluation equations were established as shown below. 


\section{Development Engineers}

Comprehensive patent strength $=0.24 * \mathrm{~A} 1+0.66 * \mathrm{~A} 2+0.59 * \mathrm{~A} 3+0.54 * \mathrm{~A} 4+0.24 * \mathrm{~A} 5$

$$
\begin{aligned}
& \mathrm{A} 1=0.70 * \mathrm{X} 1+0.64 * \mathrm{X} 2+0.68 * \mathrm{X} 3 \\
& \mathrm{~A} 2=0.42 * \mathrm{X} 7+0.59 * \mathrm{X} 8+0.59 * \mathrm{X} 14 \\
& \mathrm{~A} 3=0.36 * \mathrm{X} 6+0.65 * \mathrm{X} 10+0.74 * \mathrm{X} 11+0.39 * \mathrm{X} 12 \\
& \mathrm{~A} 4=0.48 * \mathrm{X} 4+0.63 * \mathrm{X} 5 \\
& \mathrm{~A} 5=0.74 * \mathrm{X} 9+0.39 * \mathrm{X} 13
\end{aligned}
$$

\section{Intellectual Property Department Staff}

Comprehensive patent strength $=0.36 * \mathrm{~A} 1+0.69 * \mathrm{~A} 2+0.45 * \mathrm{~A} 3+0.42 * \mathrm{~A} 4+0.56 * \mathrm{~A} 6$

$$
\begin{aligned}
& \text { A1 }=0.81 * \mathrm{X} 1+0.87 * \mathrm{X} 2+0.76 * \mathrm{X} 7 \\
& \mathrm{~A} 2=0.42 * \mathrm{X} 3+0.49 * \mathrm{X} 4+0.39 * \mathrm{X} 8 \\
& \mathrm{~A} 3=0.45 * \mathrm{X} 6+0.50 * \mathrm{X} 10+1.33 * \mathrm{X} 11 \\
& \mathrm{~A} 4=0.47 * \mathrm{X} 5+0.96 * \mathrm{X} 13+0.6 * \mathrm{X} 14 \\
& \mathrm{~A} 6=0.39 * \mathrm{X} 9+1.78 * \mathrm{X} 12
\end{aligned}
$$

\section{Chartered Patent Agents}

Comprehensive patent strength $=0.21 * \mathrm{~A} 1+0.35 * \mathrm{~A} 2+0.1 .99 * \mathrm{~A} 3+0.08 * \mathrm{~A} 4+0.22 * \mathrm{~A} 7$

$$
\begin{aligned}
& \text { A1 }=1.19 * \mathrm{X} 1+0.74 * \mathrm{X} 2+0.30 * \mathrm{X} 6+0.31 * \mathrm{X} 12 \\
& \mathrm{~A} 2=0.46 * \mathrm{X} 6+0.74 * \mathrm{X} 8+0.92 * \mathrm{X} 9+0.70 * \mathrm{X} 13 \\
& \mathrm{~A} 3=0.97 * \mathrm{X} 10+0.83 * \mathrm{X} 11+0.78 * \mathrm{X} 14 \\
& \text { A4 }=2.2 * \mathrm{X} 4+0.34 * \mathrm{X} 5 \\
& \text { A7 }=\mathrm{X} 3
\end{aligned}
$$

By means of the above procedure, the larger picture of how the development engineers, intellectual property department staff, and chartered patent agents evaluate patents has been clarified.

By preparing a radar chart through utilization of the above patent evaluation equation, the evaluation of a patent's value can be strategically visualized as shown in Figure 2. In the left diagram, the detailed evaluation is visualized and the potential factors are graphically presented in the right diagram.

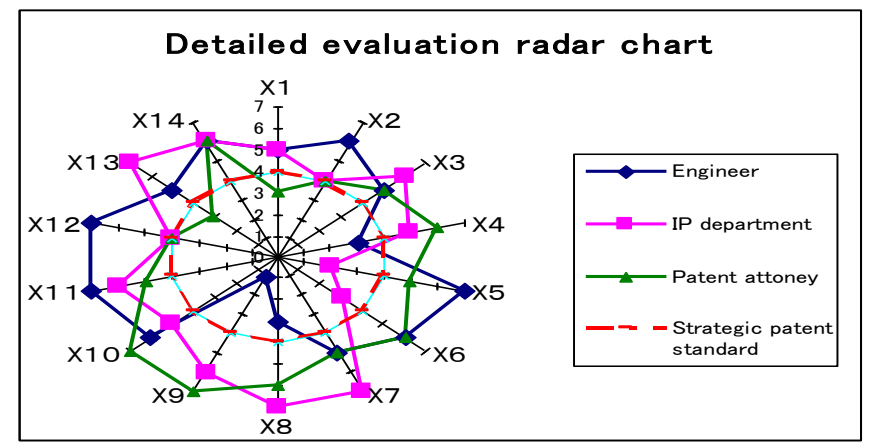

Figure 2:

(Left) Detailed Evaluation Radar Chart of Patent Power

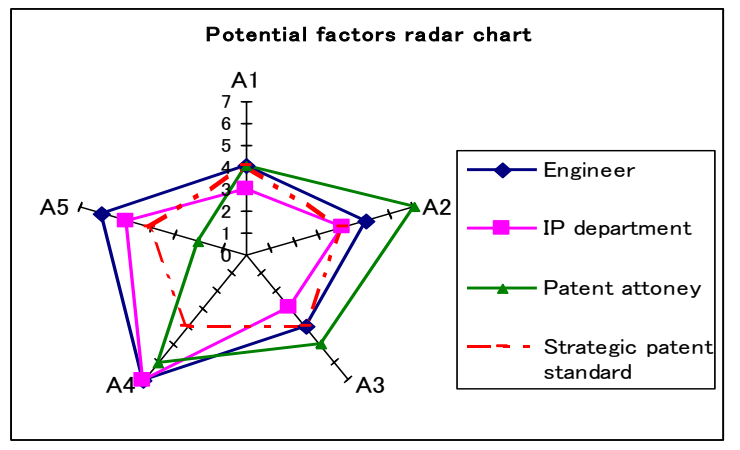

(Right) Potential Factors Radar Chart of Patent Power

\section{Creating The "A-PPM" Software}

In an effort to make the patent evaluation method generally applicable and convenient to use, it was standardized as "A-PPM" Software. Its structure and characteristics can be seen in Figures 3 and 4. When evaluating 
a patent and scoring the above mentioned explanation variables X1 to X14 from 1 to 7 points, the evaluation results can be visualized in a radar chart of the five potential factors.

Moreover, a function is provided for conducting the evaluation so that the difference in the evaluations by the three groups involved in patent acquisition (development engineers, intellectual property department staff, and chartered patent agents) will all be made clear.

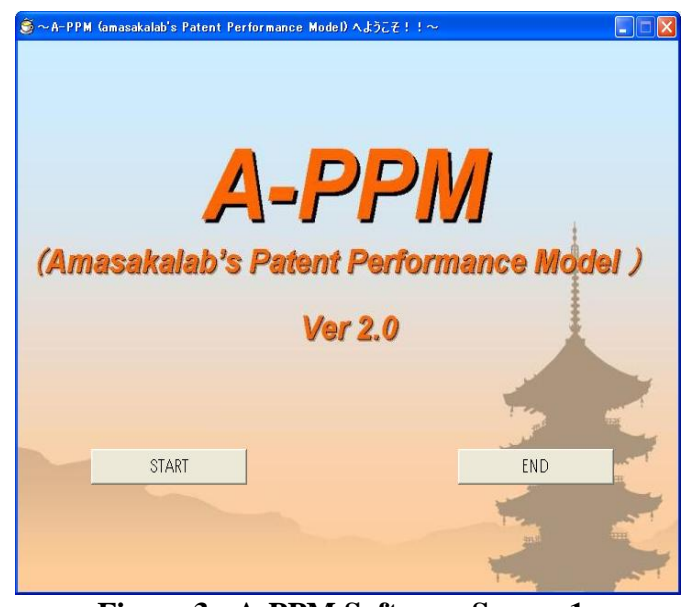

Figure 3: A-PPM Software Screen 1

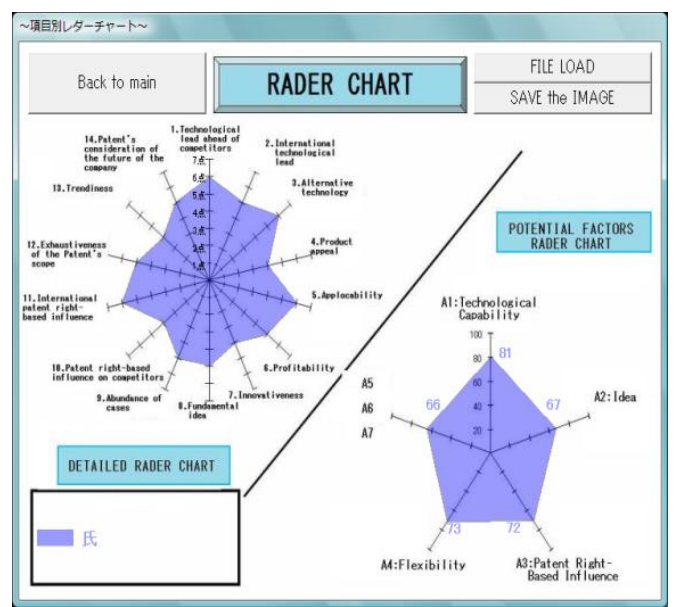

Figure 4: A-PPM Software Screen 2

By using these two radar charts, the way these three groups think about the evaluated patents, as well as their possible strong and weak points, can be clearly seen at a glance. Furthermore, the conventional subjective evaluation based on the three groups' empirical rules has been converted into an objective evaluation, and this facilitates opinion exchange among the groups as well.

"A-PPM" therefore automates the visualization process, consisting of the evaluation calculation and radar charts, and supports the convenient use of this method for those who use this software. Evaluation of patents using "A-PPM" can easily present their weak points, so that more strategic patents can be created.

\section{VERIFICATION OF THE EFFECTIVENESS OF “A-PPM"}

The authors applied the established "A-PPM" at a company so as to verify its effectiveness. Figure 5 shows an application case at Fuji-Xerox. A-PPM here was modified so as to fit the characteristics of the company.

As the figure shows, the evaluation made of application patents by 1) the development engineers in the Research Department was later supported by the 2) patent management staff from the Intellectual Property Department, and as a result, the contents of these inventions and the patents claims were successfully and strategically applied.

Similarly, the authors were able to conduct verification of "A-PPM" at other leading corporations as well, and confirmed the obtainment of the desired results. 


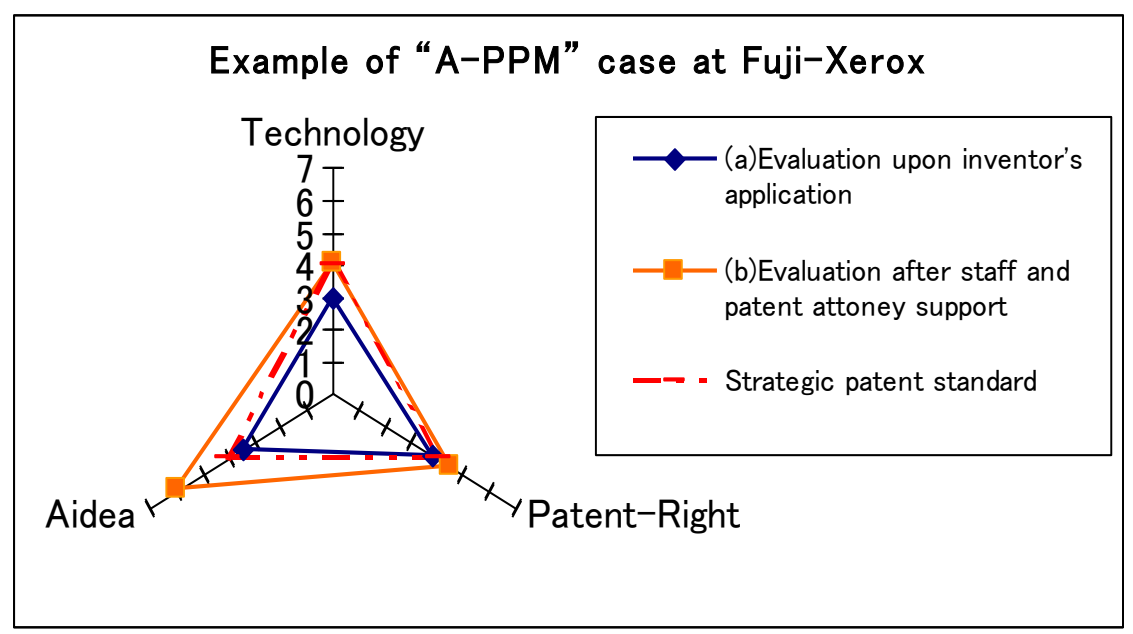

Figure 5: Example Of “A-PPM” Case At Fuji-Xerox

\section{CONCLUSION}

In this study, the qualitative evaluation method of patent value, "A-PPM" was proposed. By using this method, the difference in the patent evaluations made by three groups, development engineers, the intellectual property department staff, and chartered patent agents, who are all deeply involved in patent creation, was strategically visualized. Therefore, this method is considered to be a valid method of supporting the creation of strategic patents as a basis of corporate strategy.

\section{ABOUT THE AUTHORS}

Koichiro Anabuki is a graduate student of the College of Science and Engineering at Aoyama Gakuin University, Japan.

Haruhiko Kaneta is a graduate student of the College of Science and Engineering at Aoyama Gakuin University, Japan.

Dr. Kakuro Amasaka is a Professor in the College of Science and Engineering at Aoyama Gakuin University, Japan. He received his Ph.D. degree in Precision Mechanical and System Engineering, Statistics and Quality Control at Hiroshima University in 1997. Since joining Toyota Motor Corporation in 1968, he worked as a quality control consultant for many divisions and the General Manager of the TQM Promotion Division (1998-2000). His specialty is New JIT, Science TQM, Science SQC, Numerical Simulation (CAE) and Customer Science. Now he has been serving as the vice chairman of JSPM (2003-2007) and JOMSA (2008-), and the director of JSQC (2001-2003).

\section{REFERENCES}

1. Japan patent office. [cited 2008]. Available from: http://www.jpo.go.jp/

2. Nikkei. Corporate Innovation through Competitive Patent. 2002 June 22.

3. Amasaka K. The Validity of "TJS-PPM" Patent Value Appraisal Method in the Corporate Strategy: Development of "Science TQM". A New Principle for Quality Management (Part 3). The Japan Society for Production Research. The 17th Annual Conference. Gakushuin Univesity Tokyo. 2003; 189-192

4. Amasaka K., Nitta S., Kondo K. An Investigation of Engineers' Recognition and Feelings about Good Patents by New SQC Method. Journal of the Japanese Society for Quality Control. The 52nd Technical Conference. Tokyo. 1996; 17-24.

5. Amasaka K. Quality of Engineer's Work and Significance of Patent Application. The 2nd Patent Seminar. Aoyama Gakuin University. Tokyo, 2002. 
6. Amasaka K. Proposal and Implementation of the Science SQC. Quality Control Principle,International. Journal of Mathematical and Computer Modeling, 2003; 38: 1125-1136.

7. Amasaka K. Development of "Science TQM" A New Principle of Quality Management. Effectiveness of Strategic Stratified Task Team at Toyota. International Journal of Production Research. 2004; 42: 36913706.

8. Kevin G R., David K. Discovering New Value in Intellectual Property. Diamond Harvard Business Review. 2001 July: 98-113.

9. Umezawa K. Miscellaneous Impressions of Intellectual Property Rights. Intellectual Property Management. 1999; 49(3): 353-364.

10. Kusama H. Analysis of Technological Trend utilizing Patent Information. The 29th Japan Science and Technology Corporation. 1992; 177-182.

11. Taketomi T., Hiraguchi Y., Hirabayashi T. Evaluation of Intellectual Property Value and Recovery of Invested Resources. R\&D Management. 1997; 32-43.

12. Amasaka K. Proposal and Validity of Patent Value Appraisal Model "TJS-PVAM"- Development of "Science TQM" in the Corporate Strategy -, The Academic Journal of China-USA Business Review, 2009; 8(7): 45-56.

13. Jeffrey G. Miller, Aleda V. Roth. A Taxonomy of Manufacturing Strategies. Management Science. 1994 March; 42. 3: 285-304.

14. Mark S. Aldenderfer, Roger K. Blashfield. CLUSTER ANALYSIS. Sage Publications, The International Professional Publishers. 1984.

15. Ishigaki K., Niihara K. A Study for Objective Evaluation of Patent Value—Proposal of A-PAT”. Aoyama Gakuin University. Graduation Thesis. Amasaka-Laboratory Study Group. 2002.

16. Anabuki K., Kaneta H., Yamaji M., Amasaka K. A Study of Patent Evaluation Method "A-PPM” for Corporate Strategy. Asian Network Quality Congress. 2007; 670-678.

17. Anabuki K., Kaneta H., Yamaji M., Amasaka K. Proposal and Validity of Patent Evaluation Method. Proceedings of the Third World Conference on Production and Operation Management, Gakushuin University: August 5-8, 2008; 1276-1287.

18. Yamaji M., Sakatoku T., and Amasaka K. Partnering Performance Measurement "PPM-AS" to Strengthen Corporate Management of Japanese Automobile Assembly Makers and Suppliers. International Journal of Electronic Business Management. 2008; 6(3): 139-145. 
International Journal of Management \& Information Systems - Third Quarter $2011 \quad$ Volume 15, Number 3

NOTES 